\title{
Web-based research: Methodological variables' effects on dropout and sample characteristics
}

\author{
KEVIN M. O'NEIL and STEVEN D. PENROD \\ John Jay College of Criminal Justice, New York, New York \\ and \\ BRIAN H. BORNSTEIN \\ University of Nebraska, Lincoln, Nebraska
}

\begin{abstract}
Previous research has made a beginning in addressing the importance of methodological differences in Web-based research. The present paper presents four studies investigating whether sample type, financial incentives, time when personal information is requested, table design, and method of obtaining informed consent influence dropout and sample characteristics(both demographics and measured attitudes). Undergraduates were less likely to drop out than nonstudents, and nonstudents offered a financial incentive were less likely to drop out than those offered no incentive. Complex tables, tables that were too wide, requests for personal information on the first page, and the imposing of additional informed consent procedures each provoked early dropout. As was expected, nonstudents and those presented with complex tables showed more measurement error and attitude differences. Asking for personal information and imposing additional consent procedures affected the demographic makeup, raising challenges to external validity.
\end{abstract}

As use of the Internet and the World-Wide Web for psychological research continues to grow, the differences among Web-based research methods increase. Previous articles (Frick, Bächtiger, \& Reips, 1999; K. M. O’Neil $\&$ Penrod, 2001) have called for increased research on the effects of methodological variables associated with Web-based research. The present research focuses on sample types, financial incentives, when personal information is asked for, Web site designs, and methods for obtaining informed consent. In four studies, we hypothesized that these variables would affect dropout, but not sample characteristics. ${ }^{1}$

\section{Dropout}

Dropout should be measured and analyzed in order to detect motivational confounding (Reips, 2002a, 2002b). However, researchers can also use methodological variables to affect dropout-reducing dropout increases sample size and, thus, statistical power, whereas provoking early dropout increases the remaining sample's motivation for participating sincerely. In the present research, we investigated which variables can be used for either of these purposes.

This research constituted the first author's doctoral dissertation at the University of Nebraska-Lincoln under the guidance of Steve Penrod, Brian Bornstein, Cal Garbin, John Flowers, and Bob Schopp. Thanks to those committee members and to Robert Ray and Bridget Faimon, who provided research materials for Studies 1 and 3, respectively. Thanks also to the anonymous reviewers for their suggestions. Correspondence concerning this article should be directed to K. M. O'Neil, John Jay College of Criminal Justice, Department of Psychology, 445 West 59th Street, New York, NY 10019-1199 (e-mail: koneil@jjay.cuny.edu).
Variables that may reduce dropout include the use of financial incentives and sample type. Previous research conflicts over whether financial incentives, in the form of a lottery, reduce dropout in Web-based studies (Frick et al., 1999; Musch \& Reips, 2000; K. M. O’Neil \& Penrod, 2001). Researchers expect more dropout among nonstudents than among undergraduates (Sears, 1986), although research has not directly tested the hypothesis. Also, nonstudents recruited from different sources (e.g., through links vs. through a prearranged panel) may differ in dropout.

Variables that may provoke early dropout include asking for personal information, table design, and method of obtaining informed consent (for other variables, see Reips, 2002b). Asking for personal information, such as demographic information or an e-mail address at the beginning of a study, increases dropout at that point but then reduces dropout on later pages (Frick et al., 1999; K. M. O’Neil \& Penrod, 2001). Dillman, Tortora, Conradt, and Bowker (1998) found that a survey with a "fancy" design was completed by significantly fewer respondents, who took more time to do so, than by those who received a "plain" design. Although methods for obtaining informed consent other than just a click of a button have been suggested (Smith \& Leigh, 1997), research has not explored effects on dropout. Research is needed to identify which variables affect dropout while not affecting sample characteristics.

\section{Sample Characteristics}

The demographic and attitudinal characteristics of a sample affect its representativeness and, thus, its external 
validity. For survey research, sample characteristicsespecially attitudes - are the dependent variable of interest. As such, researchers conducting either experiments or surveys should be concerned about whether methodological variables affect sample characteristics, through dropout or otherwise. Prior research has addressed such issues with other methods of research; in the present research, we investigated such effects in Webbased research.

There are obvious demographic and attitudinal differences between undergraduates and nonstudents (Oakes, 1972; Sears, 1986). Research has not addressed whether similar differences arise as a result of different methods of recruiting nonstudents. Also, table design can affect mean values and measurement error in paper surveys (e.g., Dillman, 2000; Krosnick, 1999), but similar effects have not been investigated fully in Web-based studies (Dillman \& Bowker, 2001). Research has also not explored the effects of different methods of obtaining informed consent.

Provoking participants' privacy concerns by asking for personal information may cause non-Caucasians, women, and those with low incomes to drop out (D. O'Neil, 2001) and, perhaps, younger and less educated individuals (see Singer, Mathiowetz, \& Couper, 1993) and may also produce attitudinal differences. Regarding financial incentives, Rush, Phillips, and Panek (1978) showed that paid participants were more social and had stronger interpersonal relationships, along with personality differences. Also, a study without a financial incentive or with a small incentive may attract only those with strong attitudes toward the subject matter of the study (Groves, Cialdini, \& Couper, 1992; Groves, Singer, \& Corning, 2000).

\section{STUDY 1}

The first study sought to replicate the effects of sample type and financial incentives shown in previous studies (Frick et al., 1999; K. M. O’Neil \& Penrod, 2001) and to explore the impact of two new methodological variablesmethod of obtaining consent and Web page table design.

\section{Method}

Nonstudents were solicited through links on four Web sites ${ }^{2}$ from January 25 to June 9, 2001. Undergraduates participated from February 1 to April 13, 2001. On the first Web page nonstudent participants either were offered a chance at payment through a lottery for prizes of $\$ 50, \$ 25$, and $\$ 10$ or were not. The participants were not told any odds of winning. Since the undergraduates participated for course credit, they were not shown the first page.

The second Web page contained the text of the consent form and demographic questions. Half the participants were required to click one button below the consent form text to receive a password, which they then entered in a box before clicking another button to begin the study. The other half only had to click the button at the bottom of the page. Also, half the participants viewed "complex" tables that had one table for each question, with alternating color backgrounds and specified to be $120 \%$ of the width of participants' screens. For items asking for a Likert-type rating, a number appeared above each radio button and the response designation (e.g., strongly agree) at the far ends of the table. The "simple" design had several items within each table, used only a gray background for the head of the table, where the response choices appeared, and had a fixed width of 600 pixels. Design differences also caused an increase in download delay (see Davis \& Hantula, 2001). This manipulation was repeated for the tables on all the following Web pages.

The third Web page contained 15 questions measuring attitudes about the civil jury system. On the fourth Web page, the participants read the plaintiff's opening statement in a civil trial, the style of which was manipulated. The participants then answered 15 questions about the attorney, the statement, and sympathy toward the plaintiff and the defendant. The participants gave a preliminary verdict and rated how certain they were of that verdict. The fifth Web page presented the defense attorney's opening statement, the style of which was manipulated in the same manner as the plaintiff's. The participants answered the same questions as they had after the plaintiff 's opening statement. The final Web page of the study gave the participants who were offered a chance at payment through a lottery the opportunity to enter their personal information and gave all the participants debriefing information.

\section{Results}

There were 870 entries in the database for the nonstudents. Two hundred entries identifiable as search engines, robots, or spiders were deleted. Eighty-one duplicate entries from the same individual were removed, leaving one entry per individual. ${ }^{3}$ There were only four instances identifiable as a participant's attempting to complete the study multiple times. This left 589 unique entries in the database. There were 301 entries in the database for the undergraduate participants. Twentythree duplicate entries were removed, leaving 278 unique entries.

Dropout analyses. Table 1 presents the effect size $r$ for predictors of dropout on the first page for the nonstudents only, on the second and third pages for the nonstudents and the undergraduates combined, over the last two pages combined, and cumulatively over the course of the reaching each page is also provided. Of the 589 unique nonstudents who reached the study's first page, 114 (19.4\%) finished. Of the 278 undergraduates, 186 (66.9\%) finished. Statistics from the respective logistic regressions are in the text below. Unless indicated otherwise, predictors in all dropout analyses included all manipulated and measured methodological and substantive variables on the current or preceding pages, as well as interactions among the manipulated methodological variables and day of the week.

Using undergraduates, offering a financial incentive, and collecting data on weekends reduced dropout. The nonstudents were much less likely to continue beyond the study's second page $(47.9 \%$ vs. $71.9 \% ; B=-1.20$, Wald $=35.35, p<.001)$ or beyond the third page $(86.4 \%$ vs. $96.5 \% ; B=-1.24$, Wald $=3.81, p=.051)$ and were less likely to finish the final two pages $(62.0 \%$ vs. $93.0 \%$; $B=-1.87$, Wald $=5.54, p=.02)$ or to finish overall $(29.7 \%$ vs. $66.9 \% ; B=-1.90$, Wald $=75.55, p<.001)$. Although neither variable significantly influenced dropout at any one point, overall, the participants on the weekend $(52.5 \%$ vs. $43.7 \% ; B=0.61$, Wald $=7.61, p<.01)$ and 
Table 1

Effect Size of Predictors of Dropout at Points in Study 1

\begin{tabular}{lccccc}
\hline & \multicolumn{5}{c}{$r$ for Continuing Beyond } \\
\cline { 2 - 5 } \multicolumn{1}{c}{ Predictor } & Page 1 & Page 2 & Page 3 & Pages 4 and 5 & Overall \\
\hline Weekend & -.03 & .06 & .07 & .08 & $.11^{* *}$ \\
Payment & .01 & .05 & -.00 & .09 & $.08^{*}$ \\
Adult & & $-.23 * * *$ & $-.10^{*}$ & $-.13^{* *}$ & $-.32^{* * *}$ \\
Simple consent & & .02 & .00 & .04 & .02 \\
Simple tables & & -.01 & $.10^{* *}$ & .03 & .02 \\
Consent $\times$ payment & & $.07 *$ & $-.12^{* *}$ & .07 & $.08^{* *}$ \\
Consent $\times$ tables & 589 & 662 & .03 & $-.14 * *$ & -.05 \\
$\quad N$ reaching page & 589 & 384 & 184 & 340 & 662 \\
$\quad$ Nonstudents reaching page & & & & 114 & 384 \\
\hline
\end{tabular}

$* p<.10 . \quad * * p<.05 . \quad * * * p<.01$.

the nonstudents offered payment $(34.7 \%$ vs. $24.3 \% ; B=$ 0.49 , Wald $=4.51, p=.03$ ) were more likely to finish.

Offering a financial incentive and using additional methods to obtain informed consent interacted to provoke early dropout. In analyses of whether the participants began the study, there was a trend such that those not offered payment were less likely to begin if a password had been required to give consent but those offered payment were more likely to finish if a password had been required. On the next page, there was an opposite effect: The nonstudents not offered payment were more likely to continue if a password had been required (91.2\% vs. $80.4 \%$ ), with little difference among those offered payment $(85.7 \%$ vs. $89.6 \% ; B=-3.01$, Wald $=$ $5.98, p=.01)$. Then, over the course of the entire study, those not offered payment were less likely to finish if a password had been required to give consent $(20.2 \%$ vs. $27.8 \%$ ), but those offered payment were more likely to finish if a password had been required (40.8\% vs. $28.8 \%$; $B=0.96$, Wald $=3.98, p<.05$ ).

Complex tables also provoked dropout. In the analysis of dropout on the page of attitudinal questions, where there were the most tables, the participants who saw the simplified tables were more likely to continue (94.8\% vs. $88.6 \% ; B=0.87$, Wald $=4.24, p=.04)$. On the next page, the method of giving consent interacted with table design, since among those for whom a password was not required, those viewing simplified tables were more likely to finish $(89.0 \%$ vs. $81.3 \%$ ) but for those for whom a password had been required, those viewing simplified tables were less likely to finish $(80.0 \%$ vs. $91.3 \%$; $B=-2.23$, Wald $=6.47, p=.01$ ).

Sample characteristics. Overall, the completed sample of nonstudents $(n=114)$ was mostly female $(64.0 \%)$ and Caucasian $(82.5 \%)$, had not yet graduated college $(64.1 \%)$, was roughly evenly distributed across locations, and had a mean age of 30.4 years (range from 18 to 67 ). There was no relationship among gender, ethnicity, education, age, and the methodological variables. There were more participants from foreign countries in the condition in which payment was not offered [42.5\% vs. $\left.19.4 \% ; \chi^{2}(4)=9.89, p<.05\right]$, probably because the lottery was offered only to U.S. residents.
Given their relevance to survey research, in our analyses, we also investigated effects on attitudes, in terms of difference in means, amount of variance, and amount of measurement error. The nonstudents were more satisfied with the judicial system $[F(1,350)=19.58, p<.001]$ but also had stronger negative impressions of the civil jury system $[F(1,350)=4.34, p=.04]$. No other methodological variables produced a mean difference. Differences in amount of variance were tested using Levene's test for homogeneity of variance (Levene, 1960). Analyses showed more variance among the undergraduates on two items but more among the nonstudents on one item. Multiple-group confirmatory factor analyses (MGCFAs) were used to test differences in measurement error (see Kline, 1998) and showed more measurement error in the nonstudent sample on three items $\left[\Delta \chi^{2}(8)=19.83, p<\right.$ $.01]$. There was significantly more variance in five items and one factor when the items were presented in the large, colorful tables. MGCFA also showed more variance in one factor among the participants with the colorful large tables $\left[\Delta \chi^{2}(2)=6.23, p<.05\right]$ and more measurement error for three items when presented in the colorful large table, whereas one item had more measurement error when presented in the simple smaller table $\left[\Delta \chi^{2}(8)=51.82, p<.01\right]$. However, the latter effect was much smaller than the other three. There was also significantly more variance on three items among the participants on the weekend.

\section{STUDY 2}

Study 2 again manipulated how informed consent was obtained and, to resolve a confound in Study 1, separately manipulated table width and whether the tables contained color.

\section{Method}

Nonstudent participants were solicited by posting the link to the study on three Web sites (not the Web Experimental Psychology Lab) from November 14, 2001 to January 30, 2002.

The first page of the study displayed instructions, the text of the consent form, and seven questions about the participants' motivation for participating (asking about whether the participants were interested in the subject matter of the study, whether they were par- 
ticipating "only for the chance to win money," whether it is important to help researchers conducting psychological experiments, concerns about privacy, understanding of the study's risks and benefits, enjoyment of participating in Web-based studies, and whether Web-based studies can provide valuable information about human behavior). Three items that were conceptually similar (importance of helping researchers, enjoyment of participating, and whether studies provide valuable information) were summed to form a measure of favorable attitudes toward participating in Web-based studies $(\alpha=.84)$. The table containing these questions appeared either in black, white, and gray or in color, and width was specified as either $80 \%$ or $110 \%$ of the participants' browser screen resolution width. Also, the study was intended to manipulate whether the nonstudents were offered a lottery either for 1 prize of $\$ 250$ or for 1 prize of $\$ 100,4$ of $\$ 25$, and 10 of $\$ 5$. However, due to a programming error, this manipulation appeared only among one eighth of the participants and, thus, was not fully crossed with other variables. The majority of the participants were offered the lottery with multiple smaller prizes.

After clicking a button to begin, half of the participants were directed to a page containing six yes/no questions about information in the consent form. The participants' answers to these questions were checked using an ASP script, and the participants were redirected back to the consent text until they had answered all six questions, demonstrating understanding. The other half proceeded directly to the next Web page, containing the case facts and jury instructions.

Two substantive variables were manipulated within a mock sexual abuse trial: type of abuse and characteristics of the victim's memory for the abuse. The next Web page repeated the jury instructions and asked the participants to indicate their verdict on the charge of sexual assault of a child. The participants also rated their confidence in the verdict and their agreement with seven items measuring believability of the defendant and the victim and seriousness of the crime. There were also demographic information questions and five questions measuring the participants' beliefs about repressed memories, trauma, and therapy. Finally, the participants were asked eight completely optional yes/no questions about personal previous sexual abuse. On the last page, the participants could enter their personal information and read debriefing information.

\section{Results}

There were 1,140 entries in the database. Removing search engines and robots (41 entries) and repeated entries (111) left 988 unique participants who visited the first page. There were only two identified instances of an attempt to complete the study multiple times.

Dropout analyses. Table 2 presents the effect size $r$ for predictors of dropout on the study's first, third, and fourth pages. Because the manipulation of informed consent involved an additional page (the second page), in a separate analysis, we investigated whether the participants who reached the first page reached the third page. Of the 988 participants who visited the first page, $176(17.8 \%)$ finished.

Day of the week affected dropout early on, since the increase in percentage of those who reached the first page who began the study over the weekend approached significance $(28.8 \%$ vs. $25.0 \% ; B=0.34$, Wald $=3.63$, $p=.057)$. Also, more participants who began on the weekend continued beyond the second page $(27.9 \%$ vs. $21.1 \% ; B=0.52$, Wald $=7.98, p<.01$ ).

Using additional methods to obtain informed consent again provoked early dropout. The main effect ( $18.6 \%$ vs. $27.2 \% ; B=-0.44$, Wald $=7.52, p<.01$ ) on continuing beyond the second page was qualified by an interaction with day of the week, such that the participants were less likely to continue when given additional questions only on weekdays ( $16.1 \%$ vs. $26.9 \%$, as compared with $27.6 \%$ vs. $28.2 \%$ on weekends; $B=0.79$, Wald $=4.27, p=.04$ ). Demonstrating an opposite effect, the participants who had answered the additional questions were marginally more likely to complete the final two pages of the study $(85.9 \%$ vs. $73.4 \% ; B=0.73$, Wald $=3.61, p=.057)$. Table design did not have significant effects on dropout.

Sample characteristics. Overall, the completed sample $(n=176)$ was mostly female $(77.8 \%)$, somewhat young (48.9\% were 24 years old or younger; only $18.2 \%$ were over 42 years old), and Caucasian (83.5\%). The participants who completed the study after having to answer additional questions about informed consent were younger $\left[\chi^{2}(4)=10.28, p=.04\right]$. No other patterns of relationship were significant.

In analyses of attitudes toward participating, the participants on the weekend were more concerned about

Table 2

Effect Size of Predictors of Dropout at Points in Study 2

\begin{tabular}{|c|c|c|c|c|c|}
\hline \multirow[b]{2}{*}{ Predictor } & \multicolumn{4}{|c|}{$r$ for Continuing Beyond } & \multirow[b]{2}{*}{ Overall } \\
\hline & Page 1 & Page 2 & Page 3 & Page 4 & \\
\hline Weekend & $.06^{*}$ & $.09 * * *$ & -.05 & .07 & .00 \\
\hline Color tables & .06 & .04 & -.03 & -.10 & -.09 \\
\hline Too wide tables & -.03 & -.03 & .03 & .10 & .11 \\
\hline Many prizes & -.04 & -.05 & .06 & .00 & .05 \\
\hline Extra consent & & $-.09 * * *$ & .06 & .11 & $.13^{*}$ \\
\hline Interest in subject & & & .08 & -.07 & .02 \\
\hline Participate for money & & & .03 & -.09 & -.07 \\
\hline Concern for privacy & & & .03 & .07 & .02 \\
\hline Understand risks & & & .09 & .08 & $.11 *$ \\
\hline Pro-study attitude & & & .04 & .08 & .02 \\
\hline Consent $\times$ weekend & & $.07 * *$ & -.00 & .02 & .02 \\
\hline$N$ reaching page & 988 & 988 & 223 & 197 & 223 \\
\hline
\end{tabular}


keeping personal information safe on the Web $[M=7.57$ vs. $6.66 ; F(1,253)=39.28, p=.01]$, and there was more variance on three items among the participants on weekdays. Also, on all seven items, the scores were lower among participants viewing colorful tables (achieving significance on one item; an average mean difference of .38), and on six items, the scores were lower among the participants viewing the tables that were too wide (an average mean difference of .16). There was also more variance on all seven items when they were presented in colorful tables, the difference being significant on three items. Furthermore, in analyses of attitudes about repressed memories, the participants who were presented with colorful tables showed lower means on two items and one factor score $[F(1,166)=9.07, p<.01]$. There was also more variance on these two items and the factor score. Means were also significantly lower for two items, and both factors were lower with tables that were too wide.

\section{STUDY 3}

In Study 3, we investigated differences between nonstudent samples by recruiting participants from two sources. In the study, we also sought to replicate effects of different methods of obtaining consent and of asking for personal information at different times in a different context.

\section{Method}

Nonstudents were solicited through links on four Web sites from April 12, 2001 to January 9, 2002. The study recruited nonstudent participants through the pool of participants at studyresponse.com from December 11, 2001 to January 5, 2002. Fourteen solicitations were returned as undeliverable, for a total of 436 successful solicitations.

The first Web page included basic instructions and the consent form text. All the participants were offered a chance at payment through a lottery with prizes of $\$ 150, \$ 75$, and $\$ 25$. All the participants rated their support for the death penalty and answered three death qualification questions. For half the participants, there was an additional line at the end of the fifth paragraph in the consent form that told the participants a password to enter at the bottom of the page, whereas the other half only had to click the button at the bottom of the page. Participants who entered the wrong password in the box were given a message to reread the consent form and try again. Half the participants were given a 15 -item scale measuring attitudes toward the death penalty (see K. M. O’Neil, Patry, \& Pen- rod, in press), and the other half did not fill out this scale until the fourth Web page. Also, for the nonpool participants, the study manipulated whether the participants were given, at this point, the option to enter a name, address, and social security number (SSN). Because the participants from studyresponse.com were guaranteed anonymity by that site, the study instead manipulated whether the participants were required to enter demographic information.

The second Web page of the study presented a mock capital sentencing hearing containing manipulations regarding whether the defendant was abused as a child and his mental illness. The third Web page presented jury instructions and contained three multiplechoice questions. The fourth Web page contained the rest of the dependent and other measures. The participants rated the presence of aggravating and mitigating factors and then gave a verdict of either death or life without parole. All the participants then answered 13 questions about their beliefs about the case. The participants who had not completed the 15-item scale measuring attitudes toward the death penalty, and the participants who had not yet been given the option of entering personal information or demographic information did so here. A final page debriefed the participants.

\section{Results}

There were 1,894 entries in the database for the participants solicited through links. Removing search engines and robots (200 entries) and duplicate entries (162) left 1,432 unique entries. There were only two instances identifiable as a participant's attempting to complete the study multiple times. There were 372 entries in the database for the participants from studyresponse.com. There were no search engine entries; 48 duplicate entries were removed. Three hundred twenty-four unique entries remained in this database, for an initial response rate of $74.3 \%$ (324/436 successful solicitations).

Dropout analyses. Table 3 presents the effect size $r$ for predictors of dropout on each of the study's four pages and cumulatively over the course of the entire study after the first page. Four hundred fifty-eight $(83.3 \%$ of those who began the study; $26.1 \%$ of those who reached the first page) finished the study; 219 of those came from the studyresponse.com pool, for a completion rate of $50.2 \%$.

Collecting data from undergraduates and on weekends reduced dropout, but only on the first page. The participants from studyresponse.com were more likely to begin the study $(74.1 \%$ vs. $21.6 \% ; B=2.70$, Wald $=147.45$, $p<.001)$. The participants over the weekend were more likely to begin, but this main effect is qualified by a significant interaction, such that there was no effect among

Table 3

Effect Size of Predictors of Dropout at Points in Study 3

\begin{tabular}{lccccc}
\hline & \multicolumn{4}{c}{$r$ for Continuing Beyond } \\
\cline { 2 - 5 } \multicolumn{1}{c}{ Predictor } & Page 1 & Page 2 & Page 3 & Page 4 & Overall \\
\hline Weekend & $.09 * * *$ & -.06 & .02 & -.03 & -.04 \\
From links & $-.28 * * *$ & .01 & -.05 & -.07 & -.06 \\
Extra consent & $-.06 * *$ & .06 & .03 & -.02 & .04 \\
Personal information at front & .02 & $-.09 * *$ & -.02 & -.04 & $-.09 * *$ \\
Demographics at front & -.01 & -.01 & .04 & -.00 & .02 \\
Death penalty scale at front & .02 & -.07 & -.03 & -.05 & $-.08 *$ \\
$\quad$ & 1,756 & 550 & 520 & 485 & 550 \\
\hline$* p$ reaching page & & & & &
\end{tabular}


the pool participants $(75.0 \%$ on the weekend vs. $74.0 \%$ on weekdays) but there was among the participants solicited by links ( $29.8 \%$ vs. $19.6 \%$, respectively; $B=1.37$, Wald $=4.24, p=.04$ ).

Using additional methods to obtain informed consent and asking for personal information provoked early dropout. The participants who were required to enter a password were less likely to begin the study (28.4\% vs. $34.4 \% ; B=-0.29$, Wald $=6.25, p=.01)$. The effect of asking nonpool participants for personal information was not significant at the point when the question appeared, but the participants who had not been given the option of entering their personal information were then less likely to continue beyond the second Web page (90.3\% vs. $96.6 \% ; B=-1.13$, Wald $=4.36, p=.04)$. Similarly, of those who began the study, the nonpool participants who had not been given the option of entering their personal information on the first page of the study were less likely to finish the study $(72.7 \%$ vs. $82.0 \% ; B=$ -0.57 , Wald $=4.02, p<.05$ ).

Sample characteristics. There were no significant relationships between methodological variables and demographic categories, except for sample type. Although the entire sample was mostly female ( $76.1 \%$ overall), the pool participants who completed the study had an even higher proportion of females [83.1\% vs. $70.3 \%$ of nonpool participants; $\left.\chi^{2}(1)=9.83, p<.01\right]$. The pool participants were also older $\left[\chi^{2}(5)=59.98, p<.001\right]$ and were more likely to be married or divorced $[47.3 \%$ vs. $29.3 \%$ and $13.4 \%$ vs. $4.6 \%$, respectively; $\chi^{2}(3)=38.23$, $p<.001]$.

Analyses showed that the participants recruited from studyresponse.com were more supportive of the death penalty and had stronger pro-death penalty beliefs, as indicated by significantly higher means on 12 items and four factor scores. There was more variance among the participants who were solicited through links on 3 items and one factor. A MGCFA also showed more measurement error in 2 items among those solicited through links $\left[\Delta \chi^{2}(30)=110.35, p<.001\right]$. There were no mean differences on items or factor scores related to when the attitude scale was completed, but there was significantly more variance on 6 items and one attitude factor when the items appeared at the end of the study. MGCFA showed that the error variances for 6 items were higher when the scale appeared at the end of the study. There was less support for the death penalty among participants on the weekend, as reflected by lower means on 6 items and two factor scores and more variance on 3 items and the one factor score on the weekend. There were no mean differences or differences in variance related to how informed consent was obtained or where personal information or demographic information was asked for.

\section{STUDY 4}

Study 4 allowed the participants to choose between two different distributions of lottery prizes and manipu- lated whether demographic information was required and when personal information (name, address, and SSN) was asked for.

\section{Method}

Nonstudent participants were solicited through links on three Web sites (not the Web Experimental Psychology Lab) from October 22, 2001 to February 25, 2002. Undergraduates participated from October 25 to December 19, 2001.

On the first Web page, the nonstudents were asked to choose whether they would prefer to be entered in a lottery either with 1 prize of $\$ 500$ or with 1 prize of $\$ 100,3$ prizes of $\$ 50,6$ prizes of $\$ 25$, and 10 prizes of $\$ 10$. Odds of winning were specified as 1 in 100. The participants were told that, upon completion of data collection, the researchers would randomly choose one of those lotteries and award the prizes. For the undergraduates, this question asked, if he or she was not participating for course credit, which lottery he or she would prefer. Also, optional personal information (name, address and SSN for nonstudents; just name and SSN for undergraduates) was either asked for at this point or was not asked for until the end of the study. Then all the participants rated their agreement with five statements about their motivation for participating.

The second Web page contained three questions about the participants' risk preferences. One question asked the participants whether they would prefer to sell a product with a rare chance of a severe injury (1-in-100,000 chance of a $\$ 500,000$ injury) or with a more common chance of a less severe injury (1-in-1,000 chance of a $\$ 5,000$ injury). Another question asked the participants whether they would prefer to receive $\$ 5$ or be entered in a lottery with a 1in-100 chance of receiving $\$ 500$. Another question asked the participants how much more, in addition to a base cost, they would pay for additional safety in a product (see Geistfeld, 2001). Also, 11 items measured attitudes toward the civil jury system and corporations.

The third Web page presented a mock civil trial, including three manipulations regarding the defendant company's behavior in the face of a known risk with its product. Thirteen items measured the participants' negative opinions toward the defendant and sympathy toward the plaintiff and the defendant. The fourth Web page contained jury instructions addressing three causes of action and the award of compensatory and punitive damages. The fifth Web page asked the participants to record verdicts and damages and to provide demographic information. For half of the participants, a JavaScript validation script was used to require completion of all demographic questions. The final Web page provided debriefing information. If the participants had not entered their personal information on the first page, they did so on this page.

\section{Results}

There were 575 entries in the database for the nonstudents. Removing search engines and robots (62 entries) and duplicate entries (43) left 468 unique entries in the database. There were not any instances identifiable as a participant's attempting to complete the study multiple times. There were 333 entries in the database for undergraduate participants. Sixty duplicate entries were removed, leaving 273 unique entries.

Dropout analyses. Table 4 presents the effect size $r$ for predictors of dropout on each of the study's four pages and cumulatively over the course of the entire study after the first page. Of the 468 nonstudents that reached the first page of the study, 89 (19.9\%) finished the study. Of the 273 undergraduates who visited the first page of the study, 187 (68.5\%) finished. 
Table 4

Effect Size of Predictors of Dropout at Points in Study 4

\begin{tabular}{lccccc}
\hline \multirow{2}{*}{\multicolumn{1}{c}{ Predictor }} & \multicolumn{5}{c}{$r$ for Continuing Beyond } \\
\cline { 2 - 5 } & Page 1 & Page 2 & Page 3 & Page 4 & Overall \\
\hline Weekend & $.04 * * *$ & .02 & .02 & .01 & .07 \\
Nonstudent & $-.33 * * *$ & $-.15 * * *$ & $-.14 * *$ & $-.13 * *$ & $-.23 * * *$ \\
Personal information (PI) at front & -.02 & $.12 * *$ & .06 & .07 & .05 \\
Many prizes & & $.11 *$ & $.11 *$ & $-.11 *$ & .00 \\
Interest in subject & & $.10 *$ & .07 & .07 & .09 \\
Important to help & & .07 & .01 & $.14 * *$ & .09 \\
Concern about privacy & & .02 & .02 & -.01 & -.01 \\
Understand risks & $-.14 * *$ & $.12 * *$ & -.02 & $-.12 * *$ & $-.10 *$ \\
PI $\times$ weekend & 741 & .00 & .00 & -.01 & -.01 \\
$\quad N$ reaching page & 468 & 138 & 304 & 289 & 304 \\
$\quad$ Nonstudents reaching page & & & 114 & 103 & 304 \\
\hline
\end{tabular}

$* p<.10 . \quad * * p<.05 . \quad * * * p<.01$.

Collecting data from undergraduates reduced dropout. Again, the nonstudents were much less likely to begin the study $(29.5 \%$ vs. $73.3 \% ; B=-1.70$, Wald $=71.85$, $p<.001$ ), to continue beyond the attitudinal questions ( $82.6 \%$ vs. $97.0 \% ; B=-1.80$, Wald $=7.46, p<.01)$, the case facts $(90.4 \%$ vs. $97.9 \% ; B=-1.97$, Wald $=6.38$, $p=.01)$, and the jury instructions $(90.3 \%$ vs. $98.9 \% ; B=$ -2.19 , Wald $=5.18, p=.023$ ), and to finish overall $(78.1 \%$ vs. $96.4 \% ; B=-2.10$, Wald $=15.42, p<.001)$. Preference for multiple lottery prizes was related to reduced dropout early in the study, but the effect did not persist throughout the study. The participants who preferred multiple prizes were more likely to continue beyond the case facts $(93.5 \%$ vs. $85.8 \% ; B=0.89$, Wald $=$ $4.19, p=.04)$ and the jury instructions $(96.3 \%$ vs. $92.3 \% ; B=1.38$, Wald $=3.82, p=.051)$ but were marginally less likely to finish the final page $(B=-2.80$, Wald $=3.71, p=.054$ ).

Asking for personal information provoked early dropout. This increase in dropout on the first page appeared only among the participants on the weekend (39.3\% vs. $50.8 \% ; 47.5 \%$ vs. $43.7 \%$ on weekdays; interaction $B=-1.17$, Wald $=5.47, p=.02$ ). The opposite effect on the next page was not qualified, since the participants who had had the option of entering their personal information were more likely to continue beyond the second Web page $(94.3 \%$ vs. $87.7 \% ; B=1.05$, Wald $=$ $5.33, p=.02)$.

Attitudes toward participating were also related to dropout. The participants who indicated that they understood the study's risks and benefits more were also more likely to continue beyond the case facts $(B=0.34$, Wald $=4.96, p=.03$ ) but then were less likely to finish the study $(B=-2.10$, Wald $=4.34, p=.04)$. In the analysis of whether the participants who reached the jury instructions continued on, the participants who felt more strongly that it was important to help researchers were more likely to continue $(B=0.90$, Wald $=5.50, p=.02)$.

No multivariate analyses were conducted on whether the participants who reached the page of dependent measures finished the study, because only 5 participants dropped out. All 5 participants were in the condition requiring demographic information, a significant bivariate relationship $\left[\chi^{2}(1)=4.71, p=.03\right]$. Four of these participants were nonstudents.

Sample characteristics. Overall, the nonstudents in the completed sample $(n=89)$ were mostly female $(77.5 \%)$ and Caucasian (86.5\%), had had at least some college classes $(88.7 \% ; 48.9 \%$ had graduated college), were single or married ( $44.9 \%$ and $39.3 \%$, respectively), and were roughly evenly distributed across age and family income categories. The participants who had had the option of entering personal information on the first page were older [e.g., $33.3 \%$ vs. $12.2 \%$ between 40 and 49 , $12.5 \%$ vs. $43.9 \%$ between 22 and $29 ; \chi^{2}(5)=16.08, p<$ $.01]$.

The nonstudents indicated greater interest in the subject matter of the study $[M=7.07$ vs. $5.89 ; F(1,336)=$ $30.81, p<.001]$ and were marginally more concerned about keeping personal information safe $[M=7.41 \mathrm{vs}$. $6.93 ; F(1,336)=3.48, p=.06]$. There were no significant mean differences related to day of the week or when personal information was asked for, and there were no differences in the amount of variance related to any methodological variable.

Also, more nonstudents indicated that they would opt to receive $\$ 5$ rather than have a 1 -in-100 chance of receiving $\$ 500$ [60.5\% vs. $47.4 \% ; \chi^{2}(1)=4.94, p=.03$ ] In the responses to the attitude questions, the nonstudents had higher means on six items and on the factors measuring negative opinions about the civil jury system $[F(1,306)=13.49, p<.001]$ and the belief that a corporation should be held to a higher standard $[F(1,306)=$ $4.91, p=.03]$. There was also significantly more variance in six items and all factor scores among the nonstudents.

\section{GENERAL DISCUSSION}

Table 5 presents a summary of the effects of methodological variables on dropout and sample characteristics. Some of the discussion below interprets null results, 
Table 5

Summary of Results Regarding Manipulated Methodological Variables

\begin{tabular}{|c|c|c|}
\hline Variable & Effects on Dropout & Effects on Sample Characteristics \\
\hline Sample type & $\begin{array}{l}1 \& 4: \text { NSs more likely to drop out than UGs } \\
\text { 3: NSs from links more likely to drop out than NSs } \\
\text { from pool }\end{array}$ & $\begin{array}{l}1 \& 4: \text { Mean differences and more variance among NSs } \\
\text { 3: Mean differences and more variance among NSs } \\
\text { from links }\end{array}$ \\
\hline Financial incentives (FI) & $\begin{array}{l}\text { 1: Ps offered FI less likely to drop out than Ps not } \\
\text { offered FI } \\
\text { 4: Ps preferring multiple lottery prizes less likely } \\
\text { to drop out }\end{array}$ & $\begin{array}{l}\text { 1: No differences } \\
\text { 4: Ps preferring multiple prizes chose risky lottery } \\
\text { choice less often }\end{array}$ \\
\hline Personal information (PI) & $\begin{array}{l}3 \& 4 \text { : ME not significant at point where PI asked for, } \\
\text { but increase in dropout after that point } \\
\text { 4: Requiring demographic information had minimal ME }\end{array}$ & $\begin{array}{l}\text { 3: No differences } \\
\text { 4: Sample asked for PI younger }\end{array}$ \\
\hline Table design & $\begin{array}{l}\text { 1: Simple tables led to less dropout, especially among NSs } \\
\text { 2: No significant effects }\end{array}$ & $\begin{array}{l}\text { 1: No ME but more variance from complex tables } \\
\text { 2: Slight differences and more variance with color and } \\
\text { too-wide }\end{array}$ \\
\hline Method of consent & $\begin{array}{l}\text { 1: Interaction with FI: increase in dropout if had to } \\
\text { do more than click button among Ps not offered FI } \\
2 \& 3: \text { Increase in dropout if had to do more than } \\
\text { click button }\end{array}$ & $\begin{array}{l}1 \& 3: \text { No differences } \\
\text { 2: Younger sample with additional procedures }\end{array}$ \\
\hline
\end{tabular}

Note-Numbers indicate the study number. ME, main effect; NS, nonstudent; P, participant; UG, undergraduate.

which were hypothesized in the analyses of effects on sample characteristics. Although such a discussion should proceed cautiously, we believe our manipulations were strong enough to be detected, as evidenced by the effect of each manipulation in at least one analysis, and large sample sizes produced high statistical power to detect effects if they existed. Furthermore, all the studies were jury simulations; research should address whether subject matter moderates the effects found here.

\section{Dropout}

In the present research, we sought to identify methodological variables that could be used to increase sample size or to provoke early dropout. The results support using undergraduates and nonstudents from prearranged panels and offering a financial incentive to increase sample size. Undergraduates are readily available at most universities; the pool at studyresponse.com has, as of October, 2002, grown to over 5,700, although the pool as a whole overrepresents Caucasians and females. Knowledge Networks, Inc.'s panel, accessible through TESS (www.experimentcentral.org), also allows nationwide representative samples but is limited to studies less than 15 min long. A large, representative panel accessible to all researchers and allowing researchers to host studies on their own servers may be an ideal goal.

The results concerning financial incentives apply only to nonstudents, because undergraduates participated for course credit (multivariate analy ses were used to resolve this confound). Some situations may require offering undergraduates a financial incentive, so future research should attempt to generalize the findings to paying undergraduates. Study 1 showed that financial incentives can reduce dropout (by 10.4\%). Frick et al. (1999) found a similar effect, but K. M. O'Neil and Penrod (2001) did not. Both length (see MacElroy, 2000) and subject matter may moderate the effect of financial incentives.
Study 1 was similar in length to the latter study but had a different subject matter, suggesting the primacy of the effect of subject matter. However, this effect was qualified by an interaction with the manipulation of method of obtaining consent. This interaction was not predicted, because financial incentives were hypothesized to affect participants low in motivation, not those relatively higher in motivation that had to go through the additional procedures. Instead, financial incentives may have an effect only when participants are faced with an additional task or "hurdle" (Reips, 2000, 2002b). Future research should test this new hypothesis. In Study 3, the participants who preferred a lottery with multiple smaller prizes were more likely to continue than those preferring a single large prize. Whether a similar manipulation would influence dropout should be investigated.

Complex tables, asking for personal information, and using additional methods to obtain informed consent can all be used by researchers to provoke early dropout. These variables do not prevent participants from dropping out but may, instead, be used to reduce error variance by reducing the random responses of participants who are not motivated to participate sincerely. The present studies were long enough that dropout evened out by the end of the study, and differences in measurement error or results were not found, so these variables are especially important for shorter studies. Three points may guide future research. First, Study 1 showed that simplified tables led to decreased dropout, but Study 2 could not explain these results in terms of use of color and table width. Instead, the important variable may be subject matter, the organization of the tables, some interaction between variables, or download delay. Second, many effects were small, as can be seen in Tables 1-4, and researchers may need to combine several variables in order to achieve large effects on dropout. Similarly, requiring the participants to answer demographic ques- 
tions produced a minimal effect on dropout. Similar but stronger manipulations at the beginning of a study may have a larger effect. Third, all the variables provoked dropout equally among the nonstudents and the undergraduates (i.e., there were no interactions involving sample type in Study 1 or 4). As such, both samples include those low in motivation to participate, whose dropout can be hurried through additional methodological hurdles (Reips, 2000, 2002b).

Finally, the only attitude variable related to dropout rates in multivariate analyses was whether the participants understood the risks and benefits associated with the study. Seemingly, the items asked differed conceptually but covaried strongly, all tapping into some general attitude or motivation. In addition, the effects on dropout observed in Studies 2 and 4 were independent of the measured attitudes. As has been explained by Rogelberg, Fisher, Maynard, Hakel, and Horvath (2001), attitudes toward research are important determinants of who participates. Thus, to further explain dropout, future research should add additional measures of these attitudes and of motivation.

\section{Sample Characteristics}

In the present research, we sought to identify methodological variables that affected sample characteristics, which may be the dependent variable in surveys or may influence external validity in studies. Sample type and table design were related to sample characteristics but, unexpectedly, so were asking for personal information and method of obtaining informed consent. Nonstudents had stronger negative attitudes toward the civil jury system, and there was more measurement error among nonstudents. Both differences are not unusual, since nonstudents have more experience with the legal system and undergraduates' attitudes are less extreme (Sears, 1986), but different measures may be needed among nonstudents to reduce the measurement error.

Study 1 showed effects of table design on means and measurement error, but Study 2 could not replicate the differences when color and width were manipulated separately. These results suggest some other variable (e.g., organization, number of questions) as a moderator. Nonetheless, these results reinforce the importance of questionnaire design to Web-based research. Survey research of attitudes or personality must be particularly attentive to sampling and table design issues (Dillman \& Bowker, 2001).

Challenges to external validity are raised by the finding that a younger sample completed the study when the participants had to answer additional questions about informed consent (Study 2, but not Study 1 or 3 ) and when the participants did not have the option of entering personal information on the first page (Study 4, but not Study 3 ). These effects may be attributed to differences in dropout, since these variables also affected dropout. That is, older participants may have been more motivated to complete the study (since they were also less likely to drop out in Study 1) but more concerned about keeping personal information private and safe (in contrast to Singer et al., 1993). This effect may be moderated by subject matter, study length, and the specific method used. Future researchers should try to replicate these findings.

\section{CONCLUSIONS}

Web-based researchers should consider the methodological variables associated with doing such research. Methodological variables had consistent effects on dropout rates and can be controlled by researchers to influence sample size, especially in relatively short studies in which dropout will not be provoked by study length. As much as on paper, Web-based researchers must be mindful of how they design tables used to collect data; sample type was also expectedly related to attitudes, but differences unexpectedly appeared that were related to asking for personal information and method of informed consent. Future research must address the effects of methodological variables and the interactions between them across many substantive domains before any firm conclusions can be made.

\section{REFERENCES}

Davis, E. S., \& Hantula, D. A(2001). The effects of download delay on performance and end-user satisfaction in an Internet tutorial. Computers in Human Behavior, 17, 249-268.

Dillman, D. A. (2000). Mail and Internet surveys: The tailored design method. New York: Wiley.

Dillman, D. A., \& Bowker, D. K. (2001). The Web questionnaire challenge to survey methodologists. In U.-D. Reips \& M. Bosnjak (Eds.), Dimensions of Internet science (pp. 159-178). Lengerich: Pabst Science.

Dillman, D. A., Tortora, R D., Conradt, J., \& Bowker, D. (1998, August). Influence of plain vs. fancy design on response rates for Web surveys. Paper presented at Joint Statistical Meetings, Dallas. Retrieved August 1, 2000 from http://survey.sesrc.wsu.edu/dillman/papers.htm.

Frick, A., Bächtiger, M. T., \& REIPS, U.-D. (1999). Financial incentives, personal information and drop-out in online studies. In U.-D. Reips, B. Batinic, W. Bandilla, M. Bosnjak, L. Gräf, K. Moser, \& A. Werner (Eds.), Current Internet science: Trends, techniques, result [Aktuelle Online Forschung: Trends, Techniken, Ergebnisse]. Zurich: Online Press. Retrieved August 1, 2000 from http://dgof.de/tband99/ inhalt.html.

GEISTFELD, M. (2001). Reconciling cost-benefit analyses with the principle that safety matters more than money. New York University Law Review, 76, 114-188.

Groves, R. M., Cialdini, R. B., \& Couper, M. P. (1992). Understanding the decision to participate in a survey. Public Opinion Quarterly, 56, 475-495.

Groves, R. M., Singer, E., \& Corning, A. (2000). Leverage-saliency theory of survey participation. Public Opinion Quarterly, 64, 299-308.

KLINE, R. B. (1998). Principles and practice of structural equation modeling. New York: Guilford.

Krosnick, J. A. (1999). Survey research. Annual Review of Psychology, 50, 537-567.

LeVENE, H. (1960). Robust tests for equality of variances. In I. Olkin (Ed.), Contributions to probability and statistics (pp. 278-292). Palo Alto, CA: Stanford University Press.

MAcElroy, B. (2000). Variables influencing dropout rates in Web-based surveys. Journal of Online Research. Retrieved December 2, 2002 from http://www.quirks.com/articles/article.asp?arg_ArticleId=605. 
Musch, J., \& REIPS, U.-D. (2000). A brief history of Web experimenting. In M. H. Birnbaum (Ed.), Psychological experiments on the Internet (pp. 61-87). San Diego: Academic Press.

OAKES, W. (1972). External validity and the use of real people as subjects. American Psychologist, 27, 959-962.

O'NeIL, D. (2001). Analysis of Internet users' level of online privacy concerns. Social Science Computer Review, 19, 17-31.

O'Neil, K. M., Patry, M. W., \& Penrod, S. D. (in press). Exploring the effects of attitudes toward the death penalty on capital sentencing verdicts. Psychology, Public Policy, \& Law.

O’NeIL, K. M., \& Penrod, S. D. (2001). Methodological variables in Web-based research that may affect results: Sample type, monetary incentives, and personal information. Behavior Research Methods, Instruments, \& Computers, 33, 226-233.

ReIPS, U.-D. (2000). The Web experiment method: Advantages, disadvantages and solutions. In M. H. Birnbaum (Ed.), Psychological experiments on the Internet (pp. 89-117). San Diego: Academic Press.

REIPS, U.-D. (2002a). Internet-based psychological experimenting: Five dos and five don'ts. Social Science Computer Review, 20, 241-249.

REIPS, U.-D. (2002b). Standards for Internet-based experimenting. Experimental Psychology, 49, 243-256.

Rogelberg, S. G., Fisher, G. G., Maynard, D. C., Hakel, M. D., \& Horvath, M. (2001). Attitudes toward surveys: Development of a measure and its relationship to respondent behavior. Organizational Research Methods, 4, 3-25.

Rush, M. C., Phillips, J. S., \& PaneK, P. E. (1978). Subject recruitment bias: The paid volunteer subject. Perceptual \& Motor Skills, 47, 443449.

SEARS, D. O. (1986). College sophomores in the laboratory: Influences of a narrow data base on social psychology's view of human nature. Journal of Personality \& Social Psychology, 51, 515-530.
Singer, E., Mathiowetz, N. A., \& Couper, M. P. (1993). The impact of privacy and confidentiality concerns on survey participation: The case of the 1990 U.S. Census. Public Opinion Quarterly, 57, 465-482.

Sмiтh, M. A., \& Leigh, B. (1997). Virtual subjects: Using the Internet as an alternative source of subjects and research environment. $\mathrm{Be}$ havior Research Methods, Instruments, \& Computers, 29, 496-505.

\section{NOTES}

1. To maintain a focus on dropout and sample characteristics, analyses of effects on substantive results are not presented here. All the studies were simulations of jury decision making. Substantive results and results detailing effects of methodological variables on substantive variables are available from the first author.

2. The four sites were those maintained by the Social Psychology Network (http://www.socialpsychology.org/expts.htm), the American Psychological Society (http://psych.hanoveredu/Research/exponnetlist.html), the Web Experimental Psychology Lab (http://www.genpsy.unizh.ch/Ulf/ Lab/WebExpPsyLab.html), and the University of Nebraska-Lincoln's psychology department (http://psych.unl.edu/psychlaw/research.asp).

3. Duplicate entries for all the studies were identified by the same IP address and browser over the course of the study, with exceptions for entries for AOL users, who share dynamically assigned IP addresses. Judging from the timing of the entries, most of these entries came from participants who reloaded the first page or who returned to the beginning of the study after completing it.

(Manuscript received November 14, 2002; revision accepted for publication February 22, 2003.) 